\title{
The Terminal $\mathbf{P}$ Wave Vector in Lead $\mathbf{V}_{1}$ of the Electrocardiogram in Healthy Young Airmen
}

\author{
Lt Col P Lynch \\ MRCP, RAMC \\ British Military Hospital, Rinteln
}

SUMMARY: The terminal $P$ wave vector in lead $V_{1}$ of the electrocardiograph $\left(V_{1} P T V\right)$ was abnormal in $93(3.2 \%)$ of 3119 healthy recruits into the Royal Air Force of mean age 19 (SD 4) years. The inference that an abnormal $V_{1} P T V$ indicates left atrial enlargement should be made with caution in otherwise healthy young men.

\section{Introduction}

The $P$ wave in lead $V_{1}$ of the electrocardiogram is normally upright but occasionally shows a small terminal negative deflection, known as the $V_{1} P$ terminal vector $\left(V_{1} P T V\right)$, which has been shown to represent left atrial depolarisation alone ${ }^{1}$. In 1964 Morris et $\mathrm{al}^{2}$ gave a quantitative assessment of $V_{1}$ PTV as the product of the duration of the wave in seconds and its amplitude in millimetres and propounded that when this product was equal to or more negative than -0.04 millimetre seconds (ie. in routine electrocardiographs one small square wide and one small square deep) it was abnormal. They found this abnormality correlated with raised left atrial pressure and with mitral valve area in over $90 \%$ of cases of mitral stenosis. Since then an abnormal $V_{1}$ PTV has been found to correlate with raised ventricular end-diastolic pressure ${ }^{3}$, raised pulmonary capillary wedge pressure ${ }^{4}$ and enlarged echocardiographic left atrial dimension. ${ }^{5}$. It has been found to be abnormal in acute pulmonary oedema ${ }^{6}$, acute myocardial infarction ${ }^{7}$, hypertension ${ }^{8}$, and ischemic heart disease ${ }^{9}$, and has become generally accepted as indicating left atrial pressure or volume overload $^{10}$. Recently, and as yet inexplicably, it haș also been found to be abnormal in cor pulmonale ${ }^{11}$. While Morris found it never to be abnormal in 100 normal patients, Forfang ${ }^{12}$ found $7 \%$ of apparently normal middle-aged men had an abnormal $V_{1} P T V$. This paper examines the prevalence of the abnormal vector in healthy young airmen.

\section{Patients and Methods}

I examined the resting electrocardiograms (ECGs) of 3119 recruits to the Royal Air Force, of mean age 19 (SD 4) years, accepted as normal after routine medical examination which included chest $X$ ray and clinical examination as well as ECG. The ECG's were recorded on Siemens Mingograf equipment (frequency response $0.05-500$ herz) at a paper speed of 25 millimetres per second, and calibrated at one millivolt to 10 millimetres deflection. For ease of expression the amplitude of the terminal $\mathbf{P}$ wave deflection was measured in microvolts rather than millimetres, and since the deflection was always negative, the negative sign was omitted. Thus a $V_{1}$ PTV greater than 3 microvolt seconds was re garded as abnormal. The actual measurements werह taken horizontally and vertically from the junction of the $\mathrm{P}$ wave with the subsequent isoelectric line as described by Morris ${ }^{2}$ (Fig. 1).

\section{Results}

$\mathrm{V}_{1}$ PTV was greater than 3 microvolt seconds in $93(3.2 \%)$ of 3119 cases, and the mean abnormal value was 4.6 (SD 1.4) microvolt seconds.

\section{Discussion}

It is generally accepted ${ }^{12}$ that the resultant of left atrial depolarisation forces is at right angles to lead $V_{1}$ and that hypertrophy or dilatation causes a posterior rotation giving rise to the terminal 
negative deflection. Josephson ${ }^{13}$ et al have suggested however that an interatrial conduction defect is the cause, though others have failed to find the inferred increased time of inscription of the vector ${ }^{14}$. The resistivity of intracardiac blood is also known to influence the inscription of the surface $E_{C G}{ }^{15}$, and acute changes in hematocrit have been shown to alter the morphology of the $\mathrm{P}$ wave ${ }^{16}$. This latter may be relevant to the finding of an abnormal $V_{1}$ PTV in cor pulmonale ${ }^{11}$ and other disorders apparently confined to the right heart ${ }^{17}$. Thus while an abnormal $V_{1}$ PTV is of value in the sequential assessment following myocardial infarction ${ }^{14}$, and is often indicative of left atrial enlargement, its presence in $3 \%$ of healthy young men, and in other unassociated conditions demands that such inferences be made with caution.

\section{REFERENCES}

1 Wenger R, Hofmann-Credner D. Observations on the atria of the human heart by direct and semidirect electrocardiography. Circulation 1952; 870: 1952.

2 Morris J J, Estes E H, Whalen, R E, Thompson $H$ K, MCINTosh H D. P wave analysis in valvular heart disease. Circulation 1964; 29: 242-52.

3. Kolbel $F$, Aschermann M, Barcakova J, Vancura J. Changes in the $P$ wave terminal segment correlated with left ventricular end-diastolic pressure. Cor Vasa 1977; 19: 100-5.

4 Rubler S, Shah N N, Moallem A. Comparison of left atrial size and pulmonary capillary pressure with the $\mathbf{P}$ wave of the electrocardiogram. $A m$ Heart J 1976; 92: 73-8.

5 Chirife R, Feitosa G S, FrankL W S. Electrocardiographic detection of left atrial enlargement. Correlation of the $P$ wave with left atrial dimension by echocardiography. Br Heart J 1975; 37: 1281-5.
6 ABRAHAM A S. P wave analysis in myocardial infarction, pulmonary oedema and embolism. (\$) Am Heart J 1978; 89: 301-4.

7 DunN $\mathrm{F}$ G, BAXTER $\mathrm{R} \mathrm{H}$, MacFarlane $\mathrm{P}$ W, LAWRIE T D V. The relation of left atrial electricalo activity and pressure in myocardial infarction. $A d v$. Cardiol 1976; 16: 376-81.

8 Micallef E, Suppa G, Mezzasalma $G$. The Po wave in systemic arterial hypertension. Anomalies during treatment and their functional meaning. $G$ Ital Cardiol 1977; 7: 842-9.

9 Forfang K, Stake G. P wave terminal force and® persisting ST elevation in chronic ischemic hearty disease. Am Heart J 1976; 92: 297-301.

10 REID D S. Electrocardiography; acute myocardial infarction. Brit J Hospital Med 1978; 1: 94-110.

11 Lynch $\mathbf{P}$, WebB-PePloe $\mathbf{M} \mathbf{M}$. The $\mathbf{P}$ terminalo vector in lead $V_{1}$ of the electrocardiogram in cor pulmonale. J Electrocardiology 1981; 15: $205-8$

12 Forfang K, ERIKSSON J. Significance of an abnormal $\mathbf{P}$ terminal force in presumably healthy middlon aged men. Am Heart $J$ 1978; 96: 739-43

13 JosEphSON M E, Kastor J A, MORGANROTHCI. Electrocardiographic left atrial enlargement; elect鹿 physiologic, echocardiographic and hemodynanonc correlates. Am J Cardiol 1977; 39: 967-71.

14 Heikkla J, Hugenholtz $P$ G, Tabakin B Prediction of left heart filling pressure and कtso sequential change in acute myocardial infarctian from the terminal force of the $\mathrm{P}$ wave. $\mathrm{Br} \mathrm{Hear}$. 1973; 35: 142-51.

15 Nelson C V, Rand P W, Angelakos E T, HugENeo HOLTZ P G. Effect of intracardiac blood on the spatial vectorcardiogram. Cir Res 1972; 31: 95- 44

16 Rosenthal A, Restieaux N J, Feig S A. Influeméc of acute variations in hematocrit on the QRS cols plex of the Frank vectorcardiogram. Circulation $1971 ; 44: 456-65$.

17 Chandraratna $\mathrm{P} A \mathrm{~N}$. On the significance of am abnormal $\mathrm{P}$ terminal force in lead $\mathrm{V}_{1}$. Am Heart 1978; 95: 267-8. 